\title{
How Doctors Care for Others: Caring, Being with and Making the Difference
}

\author{
By Mariana Barstad Castro Neves, Rafaela Oliveira Grillo \& Flavia Sollero-De-Campos
}

Pontifícia Universidade Católica do Rio de Janeiro

Abstract- Although more frequent and intense on infancy, the attachment system can be triggered across the lifespan, from "the cradle to the grave." In adulthood, whenever the individual's internal working model does not have enough resources to sustain his/her insecurity, one seeks support from an attachment figure. Illness may trigger the attachment system, obliging the individual to pursue the proximity of an attachment figure. In our research on how the doctor's attachment style affects the doctor-patient relationship (Barstad-Castro Neves, 2018), we assessed the doctor's attachment style and correlated with a semi-structured interview script. One of the categories highlighted in our research was how physicians cared for their patients. The present article aims to explore, expand, and clarify the category mentioned. It is essential to discuss how the car ing and concerning doctor acts towards his/her patient, and how the caregiving system, from the lens of attachment theory, has a functio $\mathrm{n}$ in that matter. Our research may contribute to the discussion of strategies to improve the doctor-patient relationship, therefore refining patient adherence and compliance to treatment. Besides, it can also shed light on how to give support to medical professionals, starting from medical school.

Keywords: attachment theory, doctors, bedside manners, caregiving system.

GJHSS-A Classification: FOR Code: 170199

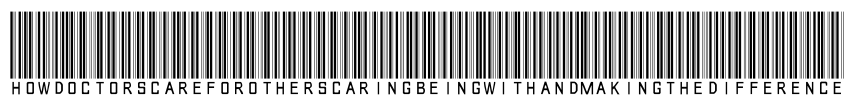

Strictly as per the compliance and regulations of:

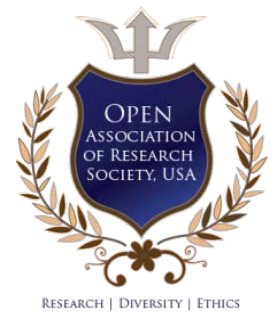

(C) 2020. Mariana Barstad Castro Neves, Rafaela Oliveira Grillo \& Flavia Sollero-De-Campos. This is a research/review paper, distributed under the terms of the Creative Commons Attribution-Noncommercial 3.0 Unported License http://creativecommons. org/licenses/by-nc/3.0/), permitting all non-commercial use, distribution, and reproduction in any medium, provided the original work is properly cited. 


\title{
How Doctors Care for Others: Caring, Being with and Making the Difference
}

\author{
Mariana Barstad Castro Neves ${ }^{\alpha}$, Rafaela Oliveira Grillo ${ }^{\circ}$ \& Flavia Sollero-De-Campos ${ }^{\circ}$
}

\begin{abstract}
Although more frequent and intense on infancy, the attachment system can be triggered across the lifespan, from "the cradle to the grave." In adulthood, whenever the individual's internal working model does not have enough resources to sustain his/her insecurity, one seeks support from an attachment figure. Illness may trigger the attachment system, obliging the individual to pursue the proximity of an attachment figure. In our research on how the doctor's attachment style affects the doctor-patient relationship (Barstad-Castro Neves, 2018), we assessed the doctor's attachment style and correlated with a semi-structured interview script. One of the categories highlighted in our research was how physicians cared for their patients. The present article aims to explore, expand, and clarify the category mentioned. It is essential to discuss how the caring and concerning doctor acts towards his/her patient, and how the caregiving system, from the lens of attachment theory, has a function in that matter. Our research may contribute to the discussion of strategies to improve the doctor-patient relationship, therefore refining patient adherence and compliance to treatment. Besides, it can also shed light on how to give support to medical professionals, starting from medical school.
\end{abstract}

Keywords: attachment theory, doctors, bedside manners, caregiving system.

\section{InTRODUCTION}

A ttachment theory states that human beings are all wired to survive and thrive. In that stance, when danger is perceived, one seeks proximity to someone stronger and wiser - the attachment figure for protection and security. The attachment figure is also connected, available, and responsive to the other, perceiving the signals of danger and the need to proximity, acting on it. It is the caregiving system.

Although more frequent and intense on infancy, the attachment system can be triggered across the lifespan. The maturity of the pre-frontal cortex and other parts of the nervous system allows the individual to construct internal working models. These models are internalized scripts of the relationship with others (and the environment), which helps the individual to predict, regulate, and respond to others. In that manner, one can build autonomy and security.

In adulthood, whenever the individual's internal working model does not have enough resources to sustain his/her insecurity (when one gets ill, for

Author a p: Ph.D in Clinical Psychology, Pontifícia Universidade Católica do Rio de Janeiro. e-mail: mbarstad@gmail.com

Author o: Master in Clinical Psychology, Pontifícia Universidade Católica do Rio de Janeiro. example), one seeks support from an attachment figure. The internal working model reflects the patterns of relationships that one has with the environment. If a secure base builds a relationship, with a responsive and available attachment figure, one will have a positive model of self and positive model of others, with low anxiety and low avoidance traits, denominated secure attachment style. If there is a negative model of self and a positive model of others, reflecting an inconsistent environment (with high anxiety level and low avoidance level), it results in a preoccupied attachment style. When a caregiver is unresponsive and inconsistent, elevating the avoidance dimension and with a low anxiety dimension, one could construct a positive model of self and a negative model of others, also known as dismissing attachment style. Finally, if one has a negative model of self and a negative model of others, resulting from sacrificing the self to adapt to the caregiver (with high anxiety and high avoidance), one will be assessed as a fearful attachment (Mikulincer \& Shaver, 2007).

Illness may trigger the attachment system, obliging the individual to seek the proximity of an attachment figure. If this figure is responsive and available, then the attachment system is deactivated, and one may feel safe to deal with his (or her) health issues. However, if the attachment figure is unavailable and unresponsive, one may need to activate secondary attachment strategies accordingly with its internal working model (Strauss \& Benk-Franz, 2016).

Healthcare professionals deal with numerous challenges: healthcare system overload, difficulty in population's accessibility to clinics and hospitals, pressure for reducing costs (sometimes in detriment to the quality of care), among others. Those issues can result in an array of different professional caring for one patient or patient access being restrict to different clinics and hospitals (without a specific physician, for example), which can mitigate the effects of the doctor-patient relationship (Hunter \& Maunder, 2016).

However, the healthcare system is built based on relationships. At any time, there will be at least two individuals involved. The distress of illness and the support provided at this moment occurs between two people in relation (Hunter \& Maunder, 2016).

"Because healthcare is inevitably and inescapably relational, understanding how relationships develop and how that development sets a precedent for later 
relationships, including those between a patient and a healthcare professional, illuminates many of our healthcare dilemmas and holds a promise of improving care" (Hunter \& Maunder, 2016, p. 05).

How the individual constructs his/her relationships with others, embodied as internal working models, can influence one's health conditions, including how he/she utilizes the healthcare system. Research shows that individuals with preoccupied attachment styles are more prone to report more physical symptoms and utilize more the healthcare system. However, this does not mean a higher collaboration with treatment. On the other hand, dismissing and fearful attachment styles have less utilization of the system, albeit fearful individuals report more physical symptoms (Ciechanowski et al., 2002; Ciechanowski et al., 2006).

Attachment patterns of security and insecurity may shed light on comprehending the doctor-patient relationship. They can help predict how the patient may react to a new diagnosis or change in treatment, allowing the physician to build communication strategies so the patient can be less resistant (Hunter \& Maunder, 2016; Strauss \& Benk-Franz, 2016).

In our research on how the doctor's attachment style affects the doctor-patient relationship (BarstadCastro Neves, 2018), we assessed the doctor's attachment style and correlated with a semi-structured interview script. The purpose of our study was to analyze how the caregiving system, as a concept of Attachment Theory, is inserted in the doctor-patient relationship.

One of the categories highlighted in our research was how physicians cared for their patients. The present article aims to explore, expand, and clarify the category mentioned. It is essential to discuss how the caring and concerning doctor acts towards his/her patient, and how the caregiving system, from the lens of attachment theory, has a function in that matter.

\section{The Doctor's Attachment Styles Assessing the Caregiving System}

Many studies relate to patient satisfaction with the doctor's communication skills and his/her emotional regulation. According to attachment theory, how an attachment figure communicates his/her responsiveness and availability engender the security felt sense in an individual (Kafetsios et al., 2015; Fletcher, McCallum \& Peters, 2016; Wallin, 2007).

In 2018, we conducted qualitative research aiming at the doctor's caregiving system and how it can have an impact on the doctor-patient relationship. Eleven physicians, specialized in hematology, from Rio de Janeiro and São Paulo, working in the Brazilian public healthcare system (SUS - Sistema Único de Saúde), were assessed and interviewed. We assessed the doctor's attachment style using the Adult Attachment Scale-Revised (AAS-R) (Abreu, 2005; Canavarro, Dias, \& Lima, 2006). This instrument is a self-report questionnaire built to evaluate one's attachment style. At the time this study was conducted, there was not a Brazilian translation for the AAS-R, so the option was the Portuguese version. Besides, we conducted a semistructured script interview to assess the relation of the doctor's care ability with his/her patient. Although the study could be conducted with an array of healthcare professionals, we chose physicians as our subjects to diminish our variable, given the uniqueness of each occupation. It is essential to say that the research was conducted compliant with ethic's conduct and that the names presented here are fictional, preserving the subjects' identities.

We assessed the attachment styles of all the eleven doctors. Using the Portuguese version of the Adult Attachment Scale-Revised (AAS-R) (Canavarro, 1995), at first, we found that all the doctors were classified as having a secure attachment. However, when we conducted a cluster analysis, which presents an overview of each category (anxiety, comfort with closeness, confidence in others), some features were highlighted (Table 1). Besides, an analysis of the professionals' pattern of discourse was conducted, correlating with the cluster analysis.

Table 1: Adult Attachment Scale-Revised results

\begin{tabular}{|c|c|c|c|c|c|}
\hline Subject & $\begin{array}{c}\text { Anxiety } \\
\text { (mean 3,0) }\end{array}$ & $\begin{array}{c}\text { Comfort with closeness } \\
\text { (mean 3,0) }\end{array}$ & $\begin{array}{c}\text { Confidence in others } \\
\text { (mean 3,0) }\end{array}$ & $\begin{array}{c}\text { Comfort/Confidence } \\
\text { (mean 3,0) }\end{array}$ & Attachment Style \\
\hline Maria & 1,5 & 4,5 & 3,33 & 3,92 & Secure \\
\hline Barbara & 1,17 & 4,5 & 4,3 & 4,42 & Secure \\
\hline Carolina & 2,50 & 4,00 & 3,83 & 3,92 & Secure \\
\hline Isabela & 2,50 & 3,67 & 3,5 & 3,58 & Secure \\
\hline Fabiola & 1,83 & 4,17 & 4,17 & 4,70 & Secure \\
\hline Alexandre & 2,00 & 4,5 & 3,67 & 4,08 & Secute \\
\hline Julia & 2,30 & 3,80 & 3,20 & 3,50 & Secure \\
\hline Paula & 2,33 & 3,33 & 3,00 & 3,17 & Secure \\
\hline Antonio & 2,33 & 3,33 & 3,00 & 4,17 & Secure \\
\hline Claudio & 2,17 & 4,83 & 3,33 & 3,16 & Secure \\
\hline Laura & 2,00 & 3,67 & 2,67 & Secure \\
\hline
\end{tabular}


In the anxiety cluster, all subjects presented scores above the mean index. At the comfort with closeness cluster, Antonio and Paula presented score discretely higher than mean (both 3,33 ), which can relate with struggle with closeness and intimacy in the relationship. Laura had the lowest score $(2,67)$ at the confidence with other cluster; with Antonio and Paulo scoring on the mean index $(3,0)$, which can also be considered low. We can infer that this result is related to difficulties in confiding in others while relating and being able to depend on this other.

In his discourse, Antonio states how meaningful is his relationship with his patients, seeing them as a whole and appreciating working with a team of different professionals. However, his pattern of a narrative is vague and distanced. Besides, he also admits a hardship with patients who need more coping mechanisms, labeling them as "pessimists" (SIC). He can cope better with patients who are more "optimists" (SIC), who "did not throw in the towel" (SIC).

Laura presents herself as a guide to her patients, stating how valuable is her relationship with them. At the same time, she reveals an avoidance in affectivity in her way of relating. From the pattern of the discourse of Antonio and Laura, it could mean a tendency to a dismissing attachment with higher avoidance traits. Both demonstrate distancing from their patients and having trouble dealing with the patient's issues in their process of coping with their illnesses (Mikulincer \& Shaver, 2007).

Paula shows a vague, non-objective, wordy, and contradictory pattern of discourse. Anxiety in taking care of others is present, with many moments without demonstrating self-care. She states when addressing how she chose hematology:

"I like hematology so much for two reasons. Like, the first one is something like... there were not many specialists that I used to see [in the healthcare system], and I could tell that sometimes it was something... I felt bad for the patient because they didn't have [hematology department]. Many towns didn't even have this specialty, you know. And even in a big city, it was tough. And there was a patient when I was a clinical intern, that was diagnosed with multiple myeloma. He was young, and it was exceedingly hard at the hospital where I worked, to be able to transfer him to another hospital with that specialty so that I can get a consult".

She also admits her fear of hurting people and how difficult it is to depend on someone (and how, when it happens, she pushes them away). From all of this, her pattern of discourse has fearful attachment style elements, demonstrating high anxiety and not being able to explore the environment (or the relationships). At the same time, there is a high avoidance, which is presented as avoidance of intimate and close relationships and focusing on her work (Bartholomew \& Shaver, 1998; Mikulincer \& Shaver, 2007).

Paula and Antonio scored the same in all clusters. However, each pattern of discourse is different and how they demonstrate to relate with their patients. While Paula tends to a fearful attachment style, Antonio's narrative tends to a dismissing attachment style, compatible with some authors who differentiate both patterns. Individuals with fearful attachment styles do not get close to the other because of their fear of being hurt or feeling rejected. On the other hand, individuals with a dismissing attachment style avoid relationships because they long for independence and self-sufficiency (Collins, 1996; Mikulincer \& Shaver, 2007).

Isabela appears, from the perspective of her cluster analysis, to have a secure attachment style. She scored 2,5 on the anxiety cluster (equivalent to low anxiety); 3,67 on the comfort with closeness item and 3,5 on the confidence in others (equivalent to low avoidance). In most of her narrative, she presents a coherent and cohesive speech. She is very objective and direct in her answers. However, she also demonstrates some distancing from the other. It is hard to differentiate if the distancing is a characteristic of her relationship with her patients, or from being interviewed because all her answers were affective distanced, no matter the topic. She manifests empathic abilities towards the patient, acknowledging the hardships of being ill. On the other hand, she describes her challenges in dealing with patients who demand more from the doctor or seek the doctor's aid with issues that are not hematologic. In that sense, one can inquire Isabela's AAS-R result when correlated with her pattern of discourse.

Maria's narrative is ingrained by welcoming the patient's needs, mainly since she specialized in Palliative Care. She highlights the relationship with the patient, stating that it is more important than the technique. At the same time, she gets frustrated when the patient does not receive her welcomingly, imagining that she "is not doing enough" (SIC) for him/her or that "anyone could do what she is doing" (SIC). She also rebounds her "desperation" after losing a patient, with high anxiety in that matter. With all this, we can state that Maria has some features of a preoccupied attachment style (Mikulincer \& Shaver, 2007).

Julia, Fabiola, and Claudio present elements in their narratives compatible with a secure attachment: clarity, affectivity, cohesion, openness. We can say the same about Carolina and Barbara.

\section{ili. Caring for Others: Caring, Being With and Making A Difference}

In the attachment theory's view, the caregiving system is present in the relationship with the other. It is activated whenever a threat is perceived, either by the 
individual or by the other being cared for. The attachment system is activated by this other, who needs a stronger and wiser figure (Barstad, 2013; Feeney \& Woodhouse, 2016). In the case of the doctor, this caregiving system is activated in the relationship with the patient.

The eleven physicians pointed to concern and care (one of the outcomes of the research) for their patients. Care and concern are shown by investing in the patient, harboring the patient's needs, and even when the doctor is distancing himself (or herself) from the patient (and his or her family) as a way of protecting oneself.

Investing in the patient means being available to all the possibilities, and "always having a card up the sleeve" (SIC), as stated by Paula, 35 years old:

"... I already try to go with another strategy. First I am going to find in medicine what else I can do, so I can't throw the sheet [she meant towel], say anything more, and when I am going to give this news, which is the worst moment, to tell the patient that the standard treatment did not work, I go with a card up my sleeve".

(Paula, 35 years)

However, the doctor can feel confused and identified with his or her patient for some reason, going beyond empathy and becoming an obstacle to the treatment itself.

"We feel enmeshed, you know. It is a very intense relationship. I treat leukemia, so there are prolonged admissions to the hospital, and you get frustrated by their history and even become friends with them. Moreover, it is even difficult to separate what is his/her issue from what is a professional issue. Because they also enmeshed things and we do the same. Anyhow, I can't do differently".

(Laura, 38 years old)

When Claudio talks about his relationship with his patient, he is very adamant that he is "all in" (SIC) in doing everything he can for his patient. He says:

"... I am kind of defiant. I go all the way with my sick patient. Like, I go all the way with my sick patient. It has... it already caused me a lot of trouble, you know, but I do not regret it. I don't go halfway. It's my personality.

(Claudio, 28 years old)

Paula, Laura, and Claudio show how doctors can be affected by their patients. It is an activation of their caregiving system - observing, evaluating, and eliminating a menace towards someone who needs to be cared for (the patient). Sometimes, on doing that can be very exhausting, or even can make the professional go over their emotional limits. When the caregiving system is activated, one reacts as his/her internal working model was built.
The internal working model, from the attachment theory's perspective, is the vision of one's relationship with the emotional environment (especially the first caregivers). Every behavior, response, and feelings of the attachment figure are internalized and organized as scripts. It provides predictability for the individual. When one assumes the role of an attachment figure, with an activated caregiving system, he/she fosters his/her behavior based on their internal working model, that is, their vision of self and others (the environment) (Bretherton \& Munholland, 2016; Mikulincer \& Shaver, 2007).

Another aspect of the doctor's care and concern is how he or she harbors the patient's needs, in the sense of how the physicians welcome all the facets of the patient's illness and healing, building a working alliance with trust. Our subjects on the research described this feature in different aspects, such as seeing the patient beyond his or her illness, or even how the doctor conducts the treatment. As we observe:

"When I think about what guides me, I think it is always harboring [the patient] ... Because of there is a bad diagnosis of healthy people. (...) So, what I think that guides every conduct I have is this harboring. Thankfully, we have many protocols; we have welldefined treatment guidelines, well-defined treatment conductions, but it is all in books. You know, we have to harbor that person's reality".

(Maria, 35 years old)

"So, I am always looking to observe what the patient brings. Not only what is he/she telling me, but also what is behind all of this. Moreover, this view, for the whole, with a lot of respect, is what mainly guides me. So, I am not the kind of person, for example, to have a sick person... I do not know... with leukemia, and he/she must take medicine. Sometimes we must fit the treatment to the person... to that. So, I look a lot to the person, to the patient, and not to the disease".

(Alexandre, 52 years old)

"Well, I think that we have to act with the patient in the best way possible, as you were in the patient's shoes, you know? So, I always try to do the best for him, as if it was for me, or for my family, you know? So, you have to put yourself in the patient's shoes; you have to see what he has been through, sometimes it's a harrowing situation. And you put yourself in his; in his shoes, and his family too, and try to do your best, you know?"

(Antonio, 38 years old)

"Well, I have a thinking process... we learn to have a kind of logical thinking process. So, you go to your patient; you go already. Like, I like people, so I have a good relationship with my patients. I like to talk. I like to know more about his or her life. So, I ask about it, because I think that when we talk, the patient's clinical 
history comes out easier. If I have a good talk, and I ask him/ her about his/her life, and all about this, things are easier. Of course, we have a thinking process, and during the conversation, I already have a diagnosis hypothesis. We have a thinking process, and maybe for some time, I am beginning to learn how to have a thinking process, not only from the disease but also from the patient as a whole".

\section{(Julia, 40 years old)}

Finally, another behavior observed by the doctors was related to placing the patients at a distance. Often, the physician acts out with much irritation due to the difficulty of the patient (or the family) in dealing with the disease, distancing themselves, rationalizing, or being very incisive in how he/she relates to the patient-family binomial. At times, the physician demonstrates his/her role in the treatment to the patient, meaning that dealing with diseases, and its emotional aspects, can be challenging. When the doctor puts the malady as something "the patient can learn from" (SIC), it can also be referenced as a defense mechanism.

"The easiest [patients] are the ones who understand better the objective, like the disease and the treatment phases. So, the ones who adhere more [to the treatment], or who don't disappear in the middle of the treatment, for example. Moreover, the ones who understand, who don't get too rebellious, like who understands that the disease happened because there is a learning experience from it. I have many patients who deal in this way, and it gets easier for us".

(Laura, 38 years old, talking about patients that are easier to deal with)

Dealing with families can be challenging by itself. Most of the doctors stated that the relationship with the families is intense. Some deal with it by making the family members his/her ally, understanding that most times, the family is part of the treatment, and their support is needed. Others prefer to be "pessimist" (SIC), so the family can comprehend the dimension of the disease or "put the family member in their place" (SIC):

"You call them [the family members], you put it in perspective, but truthfully. It is quite common for you to tell the patient what he/she has, and then they find you out side the room and ask. 'Doctor, you can tell us the truth.' I take the person's hand and say 'listen; I don't think your family member understood. Let's talk to him/her again". To show that I always speak. What I say to one person, I say it to everybody because I don't hide things. I don't like to hide things".

\section{(Alexandre, 52 years old)}

Patients being responsible for their treatment means being able to decide, along with the doctor, what is the best path for their treatment and health. However, some professionals can use this responsibility as a defense mechanism against emotional engagement. Others realize it is vital to feeling engaged with the patient, but it is also essential to know how to protect themselves from getting too involved. Otherwise, they are going to suffer.

"[When the patient is resistant,] I try to give them a nudge. I even argue with the sick patient. When a patient comes here, I always say that we are establishing a 50-50 contract. I bring in with my wisdom, with my knowledge and my art of treating and healing, and he/she brings in with the will to be cured, his/her will to be treated. If he/she doesn't have the will to be treated, then you are wasting your time. Right? I sometimes say that; on rare occasions, I say that".

(Alexandre, 52 years old)

"We have to have this connection, this relationship with the patient, even for you to have adherence to the treatment, to have the patient in your hand. Of course, if you suffer along with the patient, you are going to suffer all your professional life as a hematologist, right? Of course, you become more attached to some patients; you feel more, you know? But you got to build a kind of protection for yourself, you know? So you don't end up with a hint of sadness because there are patients who end up dying".

(Antonio, 38 years old, on how to connect to the patient and, at the same time, protect yourself)

Ofri (2013) states that medical education reinforces the stereotype of the doctor as a detached, emotionally disengaged persona, with the argument that emotions cloud judgment. Groopman (2007) declares that although the emotionally distant doctor is desired in some medical fields, the professional's moods and temperaments influence his/her medical judgment.

The desire to care, to be with, and to make a difference in the patient's life was reported in one way or another by all respondents. For example, Laura describes, with some distancing, the most uncomplicated patients to deal with are those who understand the goal. On the other hand, harboring the patient was a theme present in the reports, with doctors trying to see the patient and not just the disease. This response can often be confused with investing too much on the patient. The professional end up going beyond his/her limit so that the patient can feel comforted. However, the emotional cost for the professional is high, and he/she may even show extreme behaviors, always taking care of the other and not taking care of him/herself. 
IV

\section{Doctor's Attachment Style and Caring for Others: Clinical Applications}

Our research showed that, even though they were assessed with secure attachment styles, some characteristics demonstrate insecure attachment in some subjects. The need to care for their patients is present in all subjects, in different ways. At the same time, some use defense mechanisms to deal with their patients and to talk about them.

Harboring patient's needs is essential. It is critical to understand that, in this challenging moment, the patient will have demands for his/her doctors. Especially for hematologic diseases, which usually embodies long treatments and admissions into the hospital. Since the patient may feel overwhelmed, fearing for his/her life or preoccupied about losing his/her routine, his/her income, his/her role in the family (Botega, 2006).

Withal, even though acknowledging how important it is to be welcoming and understanding, some doctors can get frustrated when the patients do not meet their expectations accepting the welcoming or, at least, not showing it. Others feel as if the patient should take more responsibility for his/her treatment, even "giving a nudge" (SIC) on the patient or being more comfortable with patients who are more "optimistic" (SIC) or more objective. Yet, there are the ones who have mixed feelings towards the patients and project their fears and frustrations on them, and this includes making an effort to have all the answers before giving a diagnosis or treatment plan to the patient.

Groopman (2007) states that many patients want to feel seen, unique, and loved by their physician, focusing on who they are, not on the disease. However, medical education - and medical professionals - do not discuss the influence of affects in the physicians' emotions, judgments, and actions.

"There are reported observations of doctors avoiding discussion of the emotional and social impact of patients' problems because it distressed them when they could not handle these issues, or they did not have the time to do so adequately. This situation negatively affected doctors emotionally and tended to increase patients' distress".

(Ha, Anat \& Longnecker, 2010)

Studies (Ha, Andat \& Longnecker, 2010; Groopman, 2007) state that how the doctor is affected by his/her patient - if he/she stressed or if he/she has some preconceived beliefs towards the patient - it influences the doctor-patient relationship, even the professional's actions and the patient's responses to his/her treatment. When the patient feels safe enough, the outcomes may be better.
Good communication is also a key element in the doctor-patient relationship. When that dyad is embedded in an engaged, respectful, affective relationship, there is better patient satisfaction, higher adherence to the treatment, and refined coping skills on the part of the patient ( $\mathrm{Ha}$, Anat \& Longnecker, 2010).

"The three main goals of current doctor-patient communication are creating a good interpersonal relationship, facilitating the exchange of information, and including patients in decision making. Effective doctor-patient communication is determined by the doctors' 'bedside manner,' which patients judge as a major indicator of their doctors' general competence".

(Ha, Anat \& Longnecker, 2010, p. 38)

Physicians need to be more sensitive to their patients' reality, listening to their demands, and building a partnership with them (Caprara \& Rodrigues, 2011).

From an attachment perspective, when one feels ill, it will trigger his/her attachment system, leading him/her to seek a stronger and wiser attachment figure: the doctor. By definition, these professionals can contribute as a secure base, from which the patient can make the most of mentally, emotionally, and physically (Frederiksen, Kragstrup \& Dehlholm-Lambertsen, 2010; Kafetsios et al., 2015) .

Individuals with more sense of security can show more confidence in dealing with stress (Mikulincer \& Shaver, 2019). Many studies (Cherry et al., 2014; Fletcher, McCallum \& Peters, 2016) point to how medical education should certainly include improving doctor-patient relationship skills in the curriculum, especially among those with insecure attachment.

It suffices to say that, when facing illness, the proximity of the physician does have an impact on the sense of security, with attachment styles guiding how to manage this proximity. Research (Maunder et al., 2006) asserts that the doctors' perceptions of patient's difficulty are related to patient's attachment styles, especially insecure patterns.

Most studies centers on the patient's attachment style and their relations to the doctor. Costello (2013) stresses that, mostly, we care the same way we were cared for. So, it is safe to say that how the medical professional has been cared for influences the conduct that he/she is going to have with his/her patients.

Cluster analysis showed the avoidant and preoccupied aspects presented in the discourse of the interviewed doctors. When we correlated cluster analysis with discourse analysis, we could see that some subjects had a more distanced narrative, not having much patience or understanding for the patient's needs, labeling them as needing a nudge, or being pessimistic. Others showed anxiety in their narratives, sometimes going beyond their boundaries to be available and 
responsive to the patient. It is vital to highlight that insecure attachment is not a synonym of pathology for itself but shows vulnerability to managing stress and distress (Adshead \& Guthrie, 2015).

In our research, the doctors were very invested in caring for their patients. They tried to find answers to diminish their suffering and to understand and welcome the patients' needs. However, at times this behavior triggers affect dysregulation. It ends up in disengagement, frustration, or feeling enmeshed with the patient. When the emotional component enters medical education, doctors will be able to develop better strategies to cope with suffering without needing rigid defense mechanisms and feeling open to seeking support from their peers.

"The high levels of stress in medicine may reflect the fact that medicine involves professionals in constant exposure to attachment relationships. The attachment demands of the work situation interact with the individual's psychological make-up. Personality traits that may be functional at certain times might become ineffective and dysfunctional only under certain situational conditions, such as increased caring demands at home or work. Such a risky interaction may result in concerns about professional performance by doctors at work."

(Adshead, 2010)

Frederiksen et al. (2010) stated that an attachment bond to the practitioners is a valuable trait from the patient's perspective. The authors showed that, although they do not mind seeing an unfamiliar physician when needed, the patients preferred interpersonal in the relationship with the doctor. Patients with non-urgent symptoms or unworried tended not to mind seeing a different doctor. Although not dissatisfied with the new doctor, when asked, they prefer their regular doctor. "When individuals feel vulnerable in the face of major threats, they seek attachment figures to help them feel safe. When the threat is an illness, it is the doctor who is in the position to be an attachment figure" (p. 188).

One of the aspects that help the doctor-patient relationship is communication. Excellent communication between that dyad may regulate emotions, promote a better understanding of medical information, and provide a better perspective from patient's needs, perceptions, and expectations, generating better satisfaction with care (Ha, Anat \& Longnecker, 2010).

$$
\text { The physician's recognition and }
$$

acknowledgment of the patient's emotional cues of distress may have essential outcomes, such as improvement in patient's health, increased patient satisfaction, and even the doctor's better decision making. Provider's attachment styles can facilitate communication with the patient, influencing how he/she responds to patients' needs. Doctors with high attachment avoidance may struggle with their communication skills, interpersonal competence, expressivity, and flexibility, and interpersonal sensitivity, among other characteristics (Cherry, Fletcher \& O'Sullivan, 2013). "The empathic responsiveness of clinicians specific to attachment needs and fears may influence the success of the therapeutic relationship that develops" (Tan, Zimmermann \& Rodin, 2005, p. 144).

Our research may contribute to the discussion of strategies to improve the doctor-patient relationship, therefore refining patient adherence and compliance to treatment. If one understands the strategies patients use to deal with illness and the accompanied needs for care and closeness, we can help alleviate the suffering that physical illness promotes (Hunter \& Maunder, 2001).

Another clinical implication of the research conducted (Barstad-Castro Neves, 2018) is to reinforce the need to have more discussions ab out the healthcare professional relationship with his/her patient in medical education. Several studies (Adshead, 2010; Ciechanowski et al., 2004; Fletcher, McCallum \& Peters, 2016; Ofri, 2013; Groopman, 2007 ) offer evidence on how the professional leaves medical school with poor communication and coping skills with the patient, focusing more on symptoms.

The medical professional, considered as the one with health-related knowledge, expects to heal the patient - making him/her survive. At many times it is challenging to deal with limitations related to healthcare, especially when it is emotionally demanding for the doctor. Campos (2007) states that the healthcare professional is a caregiver under constant tension since he is always surrounded by suffering, vulnerability, and distress. The patients demand from the professional and put all their expectations and frustration on that figure. In turn, doctors can be reminded that they are vulnerable. So, this research can also be an opportunity for interventions with physicians. It will allow us to give support and care for those professionals that can be overlooked in their needs.

Although attachment processes do not define individuals in all their complexity, they can shed some light on how one interacts with his/her environment, especially responses to distress in medical illness (Thompson \& Ciechanowski, 2002). Finally, more studies are needed in this detrimental issue, leading the way for a more emotional and fruitful therapeutic alliance.

\section{References Références Referencias}

1. ABREU, CRISTIANO NABUCO DE. (2005). A teoria da vinculação e a prática da psicoterapia cognitiva. Revista Brasileira de Terapias Cognitivas, 1(2), 4358. Recuperado em 04 de fevereiro de 2018, de http://pepsic.bvsalud.org/scielo.php?script = sci_artt ext\&pid =S1808-56872005000200005\&lng $=$ pt\&tIng $=\mathrm{pt}$. 
2. ADSHEAD, G., \& GUTHRIE, E. (2015). The role of attachment in medically unexplained symptoms and long-term illness. BJPscyh Advances, 21(3), 167174. https://doi.org/10.1192/apt.bp.114.013045

3. ADSHEAD, G. (2010). Becoming a caregiver: Attachment theory and poorly performing doctors. Medical Education, 44(2), 125-131. https://doi.org/ 10.1111/j.1365-2923.2009.03556.x

4. BARSTAD, M. G. (2013). Do Berço ao Túmulo: A Teoria do Apego de John Bowlby e os estudos de apego em adultos. Orientador: SOLLERO-DECAMPOS, F. Dissertação de Mestrado Departamento de Psicologia, Pontifícia Universidade Católica Do Rio de Janeiro, 1-110.

5. BARSTAD CASTRO NEVES, M. G. (2018). A Relação Médico-Paciente sob a Ótica do Apego: pensando caminhos. Orientadora: Flavia Sollero-de Campos. Tese de Doutorado - Departamento de Psicologia, Pontifícia Universidade Católica do Rio de Janeiro, 1-181.

6. BARTHOLOMEW, K., \& HOROWITZ, L. M. (1991). Attachment styles among young adults: A test of a four-category model. Journal of Personality and Social Psychology, 61(2), 226-244. https://doi.org/ 10.1037/0022-3514.61.2.226

7. BOTEGA, N. (2006). Reação à doença e à hospitalização. In N. Botega (Ed.), Prática Psiquiátrica no Hospital Geral: interconsulta e emergência (2nd Edition, pp. 49-66). Porto Alegre: Artes Médicas.

8. BRETHERTON, I., \& MUNHOLLAND, K. A (2016). The Internal Working Model Construct in Light of Contemporary Neuroimaging Research. In J. Cassidy \& P. R. Shaver (Eds.), Handbook of Attachment: Theory, Research and Clinical Applications (3rd Edition, pp. 63-88). New York: The Guilford Press.

9. CAMPOS, E. P. (2007). Quem Cuida do Cuidador. Petrópolis: Editora Vozes.

10. CANAVARRO, M. C. (1995). Escala de Vinculação do Adulto, 1995.

11. CANAVARRO, M. C., DIAS, P., \& LIMA, V. (2006). A Avaliação da Vinculação do Adulto: Uma revisão crítica a propósito da aplicação da Adult Attachment Scale-R (AAS-R) na população portuguesa. Psicologia, 20(1), 155-186. https://doi. org/edssci.S0874.20492006000100008

12. CAPRARA, A.; RODRGUES, J (2004). A relação assimétrica médico-paciente: repensando o vínculo terapêutico. Ciência \& Saúde Coletiva, 9(1): 139-146.

13. CIECHANOWSKI, P. S., RUSSO, J. E., KATON, W. J., \& WALKER, E. A. (2004). Attachment theory in health care: The influence of relationship style on medical students' specialty choice. Medical Education, 38(3), 262-270. https://doi.org/10.1046/ j.1365-2923.2004.01767.x"

https://doi.org/10.1046/j.1365-2923.2004.01767.x

14. CIECHANOWSKI, P. S., WALKER, E. A., KATON, W. J., \& RUSSO, J. E. (2002). Attachment theory: A model for health care utilization and somatization. Psychosomatic Medicine, 64(4), 660-667. https:// doi.org/10.1097/01.PSY.0000021948.90613.76

15. CIECHANOWSKI, P., RUSSO, J., KATON, W., SIMON, G., LUDMAN, E., VON KORFF, M., ... LIN, E. (2006). Where is the patient? The association of psychosocial factors and missed primary care appointments in patients with diabetes. General Hospital Psychiatry, 28(1), 9-17. https://doi.org/10. 1016/j.genhosppsych.2005.07.004

16. CHERRY, M. G., FLETCHER, I., \& O'SULLIVAN, H. (2013). Exploring the relationships among attachment, emotional intelligence, and communication. Medical Education, 47(3), 317-325. https://doi.org/10.1111/medu.12115

17. (2014). Validating relationships among attachment, emotional intelligence and clinical communication. Medical Education, 48(10), 988-997. https://doi.org/10.1111/medu.12526

18. COLLINS, N. L. (1996). Working models of attachment: Implications for explanation, emotion, and behavior. Journal of Personality and Social Psychology, 71(4), 810-832. https://doi.org/10. 1037//0022-3514.71.4.810

19. COSTELLO, P. C. (2013). Attachment-Based Psychotherapy: Helping Patients Develop Adaptive Capacities. Washington: American Psychological Association.

20. FEENEY, B. C., \& WOODHOUSE, S. S. (2016). Caregiving. In J. Cassidy \& P. R. Shaver (Eds.), Handbook of Attachment: Theory, Research and Clinical Applications (3rd Edition, pp. 827-851). New York: The Guilford Press.

21. FLETCHER, I.; MCCALLUM, R.; PETERS, S. (2016). Attachment styles and clinical communication performance in trainee doctors. Patient Education and Counseling. http://dx.doi.org/10.1016/j.pec. 2016.05.019

22. FREDERIKSEN, H. B., KRAGSTRUP, J., \& DEHLHOLM-LAMBERTSEN, B. (2010). Attachment in the doctor-patient relationship in general practice: A qualitative study. Scandinavian Journal of Primary Health Care, 28(3), 185-190. https://doi.org/10. 3109/02813432.2010.505447

23. GROOPMAN, J. (2007). How Doctors Think. New York: Harcourt Publishing Company.

24. H.A., J.F.; ANAT, D.S.; LONGNECKER, N. (2010). Doctor-Patient Communication: A Review. The Ochsner Journal 10:38-43.

25. HUNTER, J.; MAUNDER, R. (2016). Advanced Concepts in Attachment Theory and Their Application to Healthcare. In: HUNTER, J.; 
MAUNDER, R. (Editors) (2016). Improving Patient Treatment with Attachment Theory: a guide for primary care practitioners and specialists. London: Springer.

26. HUNTER; J.; MAUNDER, R. (2001) Using attachment theory to understand illness behavior. General Hospital Psychiatry, v.24, issue 4, p. 177-182. https://doi.org/10.1016/S0163-8343(01) $00141-4$

27. KAFETSIOS, K.; HANTZARA, K.; ANAGNOSTOPOULOS, F.; NIAKAS, D. (2015). Doctors' Attachment Orientations, Emotion Regulation Strategies, and Patient Satisfaction: A Multilevel Analysis. Health Communication, November 2015. http://dx.doi.org/10.1080/10410 236.2014.993497

28. MAUNDER, R. G., PANZER, A., VILJOEN, M., OWEN, J., HUMAN, S., \& HUNTER, J. J. (2006). Physicians' difficulty with emergency department patients is related to patients' attachment style. Social Science and Medicine, 63(2), 552-562. https://doi.org/10.1016/j.socscimed.2006.01.001

29. MIKULINCER, M., \& SHAVER, P. R. (2007). Attachment in Adulthood: Structure, Dynamics, and Change.

30. OFRI, D. (2013). What Doctors Feel: what emotions affect the practice of medicine. Boston: Beacon Press.

31. STRAUSS, B.; BRENL-FRANZ, K. (2016) The Relevance of Attachment Theory in Medical Care. In: HUNTER, J.; MAUNDER, R. (Editors) (2016). Improving Patient Treatment with Attachment Theory: a guide for primary care practitioners and specialists. London: Springer.

32. TAN, A., ZIMMERMANN, C., \& RODIN, G. (2005). Interpersonal processes in palliative care: An attachment perspective on the patient-clinician relationship. Palliative Medicine, 19 (2), 143-150.

33. THOMPSON, D., \& CIECHANOWSKI, P.S. (2003). Attaching a new understanding to the patientphysician relationship in family practice. The Journal of the American Board of Family Practice, 16 3, 219-26.

34. WALLIN, D. (2007). Attachment in Psychotherapy. New York: The Guilford Press. 